\title{
Diversity among different isolates of Xanthomonas campestris pv. betlicola on the basis of phenotypic and virulence characteristics
}

\author{
L. Mahesha N. Sigera Nadugala ${ }^{1^{*}}$ and B.H.R.R. Amarasinghe ${ }^{2}$ \\ 1. National Science Foundation, 47/5 Maitland Place, Colombo 07. \\ 2. Department of Agricultural Biology, Faculty of Agriculture, University of Peradeniya, Peradeniya
}

Revised: 21 August 2008 ; Accepted: 18 November 2008

Keywords: Bacterial leaf blight, Piper betle L., Xanthomonas.

Betel vine (Piper betle L.) is subjected to attack by several pathogens. Damage caused due to diseases is a major constraint in production, as it causes direct damage to the consumable product. Out of bacterial diseases, the most problematic disease is the bacterial leaf blight (BLB) caused by Xanthomonas campestris pv. betlicola ${ }^{1}$. It was first reported in Sri Lanka in 1928 by Ragunathan as a serious leaf spot in betel $^{2}$. Symptoms are characterized by angular leaf spots surrounded by a conspicuous chlorotic halo. These symptoms later spread to the stem. When the disease becomes serious the leaves and internodes fall off and finally the vine dies. It is reported that most of the betel varieties that are cultivated at commercial level are susceptible to $X$. campestris pv. betlicola ${ }^{3}$.

Up to $60 \%$ incidence of this disease has been reported from major betel cultivating areas, and it can increase to about $75 \%$ during the rainy seasons ${ }^{2}$. The conditions that are favourable for the growth of the betel crop are also congenial for the development of the pathogen. Even though this is a very serious disease causing heavy crop losses, no work is reported from Sri Lanka giving information on the spread, biology and management of the bacterial leaf blight ${ }^{2}$. The only practical method available to control the disease is the use of disease free planting material obtained after indexing the propagating stock $^{2}$.

Currently there is no method to diagnose the pathogen at molecular level. It is suspected that there is a strain difference within the pathovar level, isolated from different Agroecological Zones (AEZ). Analysis of morphological characters as well as genetic material might be useful to find the strain differences, if any.
Studying them at molecular level may help to develop a sensitive and a specific probe for the detection of $X$. campestris pv. betlicola in future. Then, this probe can easily be used in plant disease diagnosis.

Betel (type Maha Maaneru) leaves and stems having typical BLB symptoms were collected from various AEZ of Sri Lanka (Table 1). Isolation of pathogen was carried out in the laboratory on the same day that the samples were collected ${ }^{4}$. Selected diseased leaves and stem pieces were first washed thoroughly in running water followed by sterile distilled water and thereafter blotted dry. No surface sterilization was done. Pieces of leaf and stem tissues obtained from the advancing margins of the lesions were transferred to petri dishes containing Sucrose Peptone Agar (SPA) and incubated at $30{ }^{\circ} \mathrm{C}$. Colonies of pure $X$. campestris pv. betlicola were obtained by sub-culturing at 2-day intervals. Pure cultures were stored at $4{ }^{\circ} \mathrm{C}$.

Colony characters (colony shape, elevation, pigment production, extracellular polysaccharide/slime production) were observed on the selective medium Yeast Dextrose Chalk Agar (YDCA). In addition, the shape of the cells was observed under the microscope. Gram's staining was done to check the Gram's reaction of the isolates ${ }^{5}$.

In the pathogenicity test, $48 \mathrm{~h}$ old cultures on SPA were suspended in sterile distilled water and bacterial cell number was adjusted to approximately $2 \times 10^{8}$ colony forming units (CFU) per $\mathrm{mL}$, [Optical density (OD) of 0.10 at $620 \mathrm{~nm}$ wave length] using a standard curve (according to McFarland scale). Twenty four hours prior to inoculation, healthy and actively growing betel 
vines (type Maha Maaneru) in pots were kept in a moist chamber. The temperature and relative humidity inside the chamber were maintained between $21-23{ }^{\circ} \mathrm{C}$ and $75 \%$, respectively. Betel leaves were inoculated with the bacterial suspension $\left(2 \times 10^{8} \mathrm{CFUs} / \mathrm{mL}\right)$ by spraying both surfaces of all the leaves of test plants with a low pressure hand sprayer. The leaves were wounded by a tooth pick close to mid rib at three places before inoculation. Null reaction of pathogenicity was carried out by spraying sterile distilled water on both surfaces of the control plants

Table 1: Description of collected samples

\begin{tabular}{|c|c|c|c|}
\hline District & $\begin{array}{l}\text { Agroecological } \\
\text { Zone (AEZ) }\end{array}$ & Location & Isolate code \\
\hline \multirow[t]{3}{*}{ 1. Colombo } & WL 3 & 1. Papiliyana & X.101 \\
\hline & & 2. Hokandara & X.102 \\
\hline & & 3. Godagama & X.103 \\
\hline \multirow[t]{3}{*}{ 2. Kegalle } & WL 2 & 1.Wewaldeniya & X.201 \\
\hline & & 2. Galigamuwa & X.202 \\
\hline & & 3. Nelumdeniya & X.203 \\
\hline \multirow[t]{3}{*}{ 3. Gampaha } & WL 3 & 1.Viragula & X.301 \\
\hline & & 2. Kirindiwela & X.302 \\
\hline & & 3. Kannimhara & X.303 \\
\hline \multirow[t]{3}{*}{ 4. Kalutara } & WL 3 & 1. Horana & X.401 \\
\hline & & 2. Agalawatte & X.402 \\
\hline & & 3. Panadura & X.403 \\
\hline \multirow[t]{3}{*}{ 5. Kandy } & MW 2 & 1. Meewathura & X.501 \\
\hline & & 2. Katugasthota & X.502 \\
\hline & & 3. Thalathuoya & X.503 \\
\hline \multirow[t]{3}{*}{ 6. Galle } & WL $4 \&$ WL 3 & 1.Ambalangoda & X.601 \\
\hline & & 2.Yakkalamula & X.602 \\
\hline & & 3.Ginthota & X.603 \\
\hline \multirow[t]{3}{*}{ 7. Kurunegala } & IL 1 & 1. Dambadeniya & X.701 \\
\hline & & 2. Narammala & X.702 \\
\hline & & 3. Welikare & X.703 \\
\hline
\end{tabular}

Note: WL - Low country Wet zone

MW - Mid country Wet zone

IL - Low country Intermediate zone

in which leaves were pricked at three places close to mid rib. Each isolate had three replicates. After inoculation, plants were placed again in the moist chamber where the temperature and relative humidity were maintained between $21-23{ }^{\circ} \mathrm{C}$ and $75 \%$, respectively for 30 days.

All isolates produced mucoid, convex, shiny, colonies with yellow colour pigment (Xanthomonadin) and extracellular polysaccharide slime, which confirmed that the isolates belong to the genus Xanthomonas. All isolates were Gram-negative and the cells were rod shaped which gave additional evidences about the identity of the isolate. The yellow colour pigment of isolates showed slight differences in colour intensity. The \% CYM values are given in Table 2. For further confirmation, a pathogenicity test was conducted. According to literature the blight symptoms on betel is caused only by $X$. campestris pv. betlicola and the pathogen is highly host specific $^{6}$. All the isolates produced disease symptoms on betel plants. These evidences confirmed that the isolates belong to the $X$. campestris pv. betlicola group.

Table 2: Colour intensity of the polysaccharide slime, produced by different Xanthomonas isolates, on yeast extract chalk agar according to INVAM colour chart, Morgantown, $\mathrm{WV}^{8}$.

\begin{tabular}{cl}
\hline Isolate code & $\%$ CYM \\
\hline X.101 & $0,100,40$ \\
X.102 & $0,90,10$ \\
X.103 & $0,80,10$ \\
X.201 & $0,80,40$ \\
X.202 & $0,100,40$ \\
X.203 & $0,100,20$ \\
X.301 & $0,40,0$ \\
X.302 & $0,60,0$ \\
X.303 & $0,100,10$ \\
X.401 & $0,90,10$ \\
X.402 & $0,90,10$ \\
X.403 & $0,70,0$ \\
X.501 & $0,70,0$ \\
X.502 & $0,80,10$ \\
X.503 & $0,40,0$ \\
X.601 & $0,40,0$ \\
X.602 & $0,60,0$ \\
X.603 & $0,40,0$ \\
X.701 & $0,70,0$ \\
X.702 & $0,100,10$ \\
X.703 & $0,80,0$ \\
\hline Note: CYM - Cyan, Yellow, Magenta
\end{tabular}

Variation was observed in the level of virulence among isolates. The number of days taken for initial symptom development varied from 15-28 days. Number of lesions produced ranged from 4-6 and the average diameter of the lesions varied between $5-15 \mathrm{~mm}$. The data was analyzed using Average Linkage Cluster Analysis method by the SAS package to assess the diversity among the isolates.

The development of the disease usually takes place within seven days after inoculation under favourable conditions (Temperature $27{ }^{0} \mathrm{C}-30{ }^{\circ} \mathrm{C}$, R.H. $\left.75 \%\right)^{7}$. The delay in disease development in the experiment may be due to 


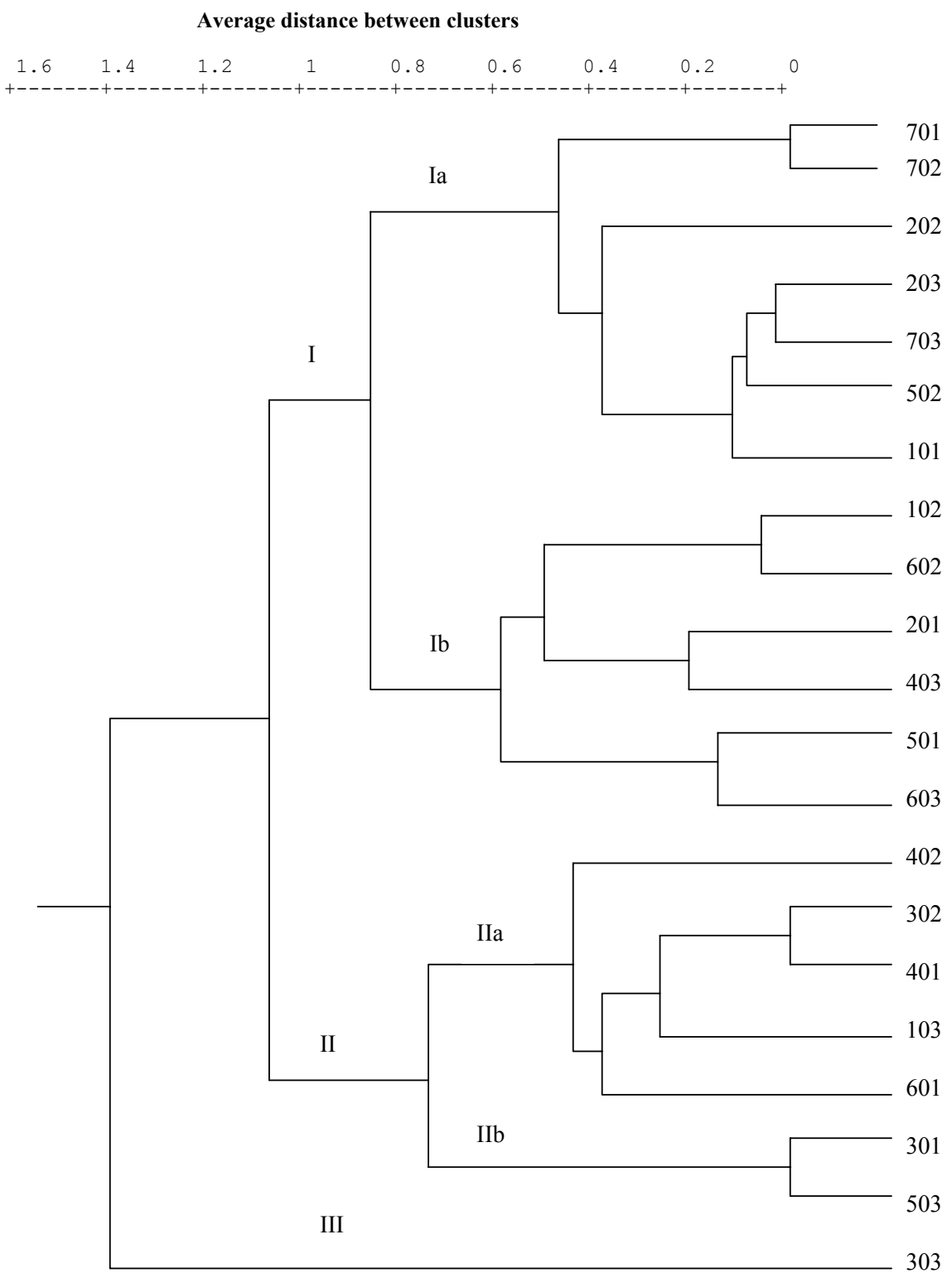

Figure 1: Dendogram showing the different clusters of $X$. campestris pv. betlicola isolates, obtained by Average Linkage Cluster Analysis of three parameters related to virulence level

low ambient temperature $\left(21{ }^{\circ} \mathrm{C}-23{ }^{\circ} \mathrm{C}\right)$ that prevailed, during experimentation.

All plants used for the pathogenicity test were at the same growing stage, belonging to the same type Maha Maaneru and were obtained from the same nursery. Therefore, it can be stated that the variation due to host factors is negligible. Initial amount of inoculum used for the test was also the same. So, the variation in the parameters measured should be mainly due to genetic variation among the isolates.
Interestingly, each cluster consisted of isolates from different districts, which showed that the genetic make up of the isolate does not depend on climatic factors/ geological distribution. This may be due to the fact that betel plants are distributed all over the country and are propagated by means of vegetative cuttings.

In cluster analysis, normalized Relative Mean Standard (RMS) distance gives a measure of variation among the isolates. For example, normalized RMS distance between isolate code X.701 and X.702 was 0.00, which shows that those two isolates are identical with 
regard to the parameters measured. Accordingly, 3 main clusters can be identified in the resulted dendogram.

Cluster I had normalized RMS distance value from 0.00-0.60 and were distributed in two subgroups (Ia and Ib). Cluster II also contained two subgroups (IIa and IIb). These results indicate the presence of a considerable phenotypic variation among the isolates indicating a high potential for genetic variability among these isolates as well. Evidence for this genetic variability should therefore be sorted at molecular level. Cluster III differed greately from the rest by having a normalized RMS of 1.4. When all these factors are summarized, it was clear that there are variations in the intensity of the colour of the pigment and the level of virulence. It can be concluded that there is a considerable phenotypic variation among the isolates as well. When this variation was assessed using Average Linkage Cluster Analysis method, three main clusters of isolates (I, II and III) with respect to pathogenicity were identified. Both clusters I and II contained two subgroups, which indicates that there is a significant variability within a cluster too. Cluster III (Isolate code X.303) showed a clear deviation from the rest of the isolates and hence was considered as a separate strain. Evidence of genetic variability will be confirmed by a molecular method in a further study.

\section{References}

1. Patel M.K., Kulkarni Y.S. \& Dhande G.W. (1951). Bacterial leaf-spot of castor. Current Science 20:106.

2. Seneviratne J.M. \& Ratnasoma H.A. (1995). Betel cultivation. Department of Export Agriculture, Gatambe, Peradeniya.

3. Nema A.G. (1988). Varietal resistance in betel vine against Xanthomonas campestris pv. betlicola and its manipulation with crop nutrients. Indian Phytopathology 41(3):344 - 350.

4. Lelliott R.A. \& Stead D.E. (1987). Methods for the Diagnosis of Bacterial Diseases of Plants. pp. 203-205. Blackwell, Oxford, UK.

5. Schaad N.W. (1980). Laboratory Guide for Identification of Plant Pathogenic Bacteria. pp. 1,15,45,46. American Phytopathological Society) St. Paul, Minnesota, USA.

6. Bhale M.S., Chaurasi R.K. \& Nayak M.L. (1985). Association of Colletotrichum capsici with Xanthomonas campestris pv. betlicola incitant of leaf spots of betel vine. Indian phytopathology 38:565 - 566.

7. Warnikar A.G., Nayak M.L. \& Bhale M.S. (1987). Survival of Xanthomonas campestris pv. betlicola in betel leaves and vine debris. Indian Phytopathology 40(3):409 - 410.

8. INVAM colour chat. http://invam.caf.wvu.edu. Accessed in November 2006. 